\title{
Multidecadal changes in winter circulation-climate relationship in Europe: frequency variations, within-type modifications, and long-term trends
}

\author{
Marcel Küttel · Jürg Luterbacher • \\ Heinz Wanner
}

Received: 13 July 2009/Accepted: 23 December 2009/Published online: 19 January 2010

(C) Springer-Verlag 2010

\begin{abstract}
Using pressure fields classified by the SANDRA algorithm, this study investigates the changes in the relationship between North Atlantic/European sea level pressure (SLP) and gridded European winter (DJF) temperature and precipitation back to 1750 . Important changes in the frequency of the SLP clusters are found, though none of them indicating significant long-term trends. However, for the majority of the SLP clusters a tendency toward overall warmer and partly wetter winter conditions is found, most pronounced over the last decades. This suggests important within-type variations, i.e. the temperature and precipitation fields related to a particular SLP pattern change their characteristics over time. Using a decomposition scheme we find for temperature and precipitation that within-type-related variations dominate over those due to changed frequencies of the SLP clusters: Approximately 70\% (60\%) of European winter temperature (precipitation) variations can be explained by within-type changes, most strongly expressed over Eastern Europe and Scandinavia. This indicates that the current European winter warming cannot be explained by
\end{abstract}

\section{Küttel $(\bowtie) \cdot H$. Wanner}

Oeschger Centre for Climate Change Research (OCCR), University of Bern, Hallerstrasse 12, 3012 Bern, Switzerland e-mail: kuettel@giub.unibe.ch

\section{Küttel · H. Wanner}

Institute of Geography, Climatology and Meteorology, University of Bern, Hallerstrasse 12,

3012 Bern, Switzerland

H. Wanner

e-mail:wanner@giub.unibe.ch

\section{J. Luterbacher}

Department of Geography, Climatology,

Climate Dynamics and Climate Change,

Justus-Liebig University of Giessen, Giessen, Germany

e-mail: juerg.luterbacher@geogr.uni-giessen.de changed frequencies of the SLP patterns alone, but to a larger degree by changed characteristics of the patterns themselves. Potential sources of within-type variations are discussed.

Keywords Circulation classification . Frequency variations - Within-type variations . Multidecadal climate variability · Europe $\cdot$ North Atlantic

\section{Introduction}

European climate is known to be strongly related to the state of the atmospheric circulation (Walker and Bliss 1932; Trenberth 1995; Hurrell and Van Loon 1997; Jacobeit et al. 2001; Slonosky et al. 2001; Xoplaki et al. 2004; Beck et al. 2007). Particularly during winter (DJF) season advective processes exerted by the large-scale atmospheric circulation have a dominant influence on the spatial distribution and temporal variation of European climate. A better understanding of the relationship between the atmospheric circulation and European climate is therefore essential when assessing the driving mechanisms behind past and current climate variability (e.g. Luterbacher et al. 2010 and references therein). With its wealth of long instrumental measurements as well as documentary and natural proxies, Europe offers the potential to address changes in this relationship in detail over a timescale extending well beyond the 20th century.

Several studies have shown that the relationship between simple time series of atmospheric modes such as the North Atlantic Oscillation and European/Mediterranean winter temperature and precipitation is subject to important decadal to multidecadal variations (e.g. Jacobeit et al. 2001; Pozo-Vázquez et al. 2001; Slonosky et al. 2001; Xoplaki et al. 2004; Haylock et al. 2007; Beranová and Huth 
2008; Vicente-Serrano and López-Moreno 2008). These variations can partly be related to changes in the atmospheric dynamics including variations in location, strength, and spatial extension of and interaction between the Azores High, the Icelandic Low, and the cold Western Russia/ Scandinavian High. Simple indices of the atmospheric circulation, though, cannot account for such internal circulation dynamics, pointing toward the need to consider the full field information on the large-scale atmospheric circulation (e.g. Jones et al. 1999; Luterbacher et al. 2000, 2002).

Studies relating changes in surface climate to spatial fields of the large-scale atmospheric circulation are mostly based on classified pressure fields, i.e. the pressure fields of the period of interest are grouped into a small number of representative patterns. For other methods than classification used to investigate the circulation-climate relationship, the reader is referred to e.g. Jacobeit (2009). Classifying pressure fields has a long tradition and has over the last couple of decades yielded a large number of approaches and methodologies (see e.g. Huth et al. 2008 for a recent overview). A general distinction can be made between subjective (manual) classifications (e.g. Hess and Brezowsky 1952; Lamb 1972) and objective (statistical/ automated) classifications. The latter became more commonly used over the last few decades with the increase in computing power. They are based on statistical methods and include various techniques based on correlations (e.g. Lund 1963; Schmutz and Wanner 1998; Brinkmann 1999) or on EOF and cluster analysis (e.g. Beck 2000; Luterbacher et al. 2001; Jacobeit et al. 2003; Philipp et al. 2007). Several studies (e.g. Beck 2000; Jacobeit et al. 2003, 2009; Beck et al. 2007; Philipp et al. 2007; Jones and Lister 2009) have investigated whether the changes in past European climate are due to variations in the frequency of particular circulation patterns or rather due to so-called within-type variations. Within-type variations comprise all changes in climate which cannot be related to changed frequencies of the circulation patterns but must rather be attributed to changed characteristics of the patterns themselves (e.g. Barry and Perry 1973; Yarnal 1993; Brinkmann 1999). This means that a particular pattern of the largescale atmospheric circulation can be related to distinctly different responses of the temperature and precipitation field. Using a decomposition scheme, Beck et al. (2007) found that roughly 53\% (64\%) of the changes in Central European mean January temperature (precipitation) over the period 1780-1995 can be related to within-type variations while the remaining percentages are due to changed frequencies of the circulation patterns. These findings are in agreement with other studies, suggesting that withintype variations are more important than frequency-related variations in explaining changes in European temperature and precipitation (e.g. Jacobeit et al. 2003, 2009; Philipp et al. 2007; Jones and Lister 2009). These studies either used spatial averages of temperature and precipitation or instrumental measurements from single stations. Furthermore, they either covered the post-1850 instrumental period (Philipp et al. 2007; Jacobeit et al. 2009; Jones and Lister 2009) or used sea level pressure (SLP) reconstructions with reduced reliability over the North Atlantic Ocean (Jacobeit et al. 2003; Beck et al. 2007).

The present study further elaborates in this direction but marks the first attempt to investigate the circulation dynamics behind changes in European temperature and precipitation not only at single stations or for spatial averages but for spatial fields. We use gridded reconstructions of European winter (DJF) SLP, temperature, and precipitation fields covering the period 1750-2000. This allows for more insights into spatial details of the changes in the relationship between representative patterns of the large-scale atmospheric circulation and European climate. Particularly, it enables to spatially distinguish temperature and precipitation variations due to frequency and due to within-type changes of the SLP patterns. Furthermore, we use a new gridded SLP reconstruction (Küttel et al. 2009) with increased skill over the oceanic region of the eastern North Atlantic. This reconstruction is expected to provide more reliable insights into the European winter climate dynamics of the last 250 years than earlier studies mentioned above. Finally, this study addresses changes in European climate due to withintype modifications and frequency variations at multidecadal timescale. This provides the unique opportunity to analyse these changes not only at spatial scale but also for different time periods.

\section{Data}

Küttel et al. (2009) statistically reconstructed seasonal gridded $\left(5^{\circ} \times 5^{\circ}\right)$ North Atlantic and European SLP fields back to 1750 by combining terrestrial instrumental pressure series and marine wind information from ship logbooks. Details on the reconstruction can be found in Küttel et al. (2009). Compared to earlier SLP reconstructions (e.g. Jones et al. 1999; Luterbacher et al. 2002) the new SLP dataset is more reliable over the eastern North Atlantic as it incorporates marine wind information from ship logbooks (Küttel et al. 2009). This allows a more realistic representation of the position and strength of the Azores High and Icelandic Low driving weather and climate downstream. In order to capture the full spatial extent of the atmospheric centres of action, we recalculated the reconstruction to cover $70^{\circ} \mathrm{W}-50^{\circ} \mathrm{E}$ and $20^{\circ} \mathrm{N}-80^{\circ} \mathrm{N}$, using the same data and method as in Küttel et al. (2009). The reconstruction quality in the extended area is similar to Küttel et al. (2009) with particularly high skill over continental Europe and the southern North Atlantic. 
However, lower quality is found over the northwestern Atlantic prior to the 19th century. The reconstruction is in the present study used for the full 1750-2000 period, i.e. we did not splice the reconstruction with the HadSLP2 (Allan and Ansell 2006) data that have been used for calibrating the statistical models 1887-2002. The derived results are similar if the reconstruction is spliced with the instrumental HadSLP2 data for the post-1886 period (not shown).

Gridded winter temperature (Luterbacher et al. 2004, reprocessed by Luterbacher et al. 2007) and precipitation (Pauling et al. 2006) reconstructions were used to investigate the relationship between the large-scale atmospheric circulation and the European climate fields over the period 1750-2000. These reconstructions are entirely independent from Küttel et al. (2009), i.e. they share no common predictors. Both datasets have a spatial resolution of $0.5^{\circ} \times 0.5^{\circ}$ and cover European land areas. For both datasets the reconstruction is spliced with the 20th century data from Mitchell and Jones (2005). For details on the reconstructions we refer to the original publications. Figure 1 shows the field averaged skill of the three reconstructions, expressed by the Reduction of Error score (RE; Cook et al. 1994). The values are above zero, indicating better skill than climatology, and continuously increase in time, reflecting the more data that become available.

\section{Methods}

In a first step, the winter SLP fields by Küttel et al. (2009) back to 1750 were grouped into representative patterns. As mentioned in the introduction, different classification techniques exist. Recently, Philipp et al. (2007) introduced

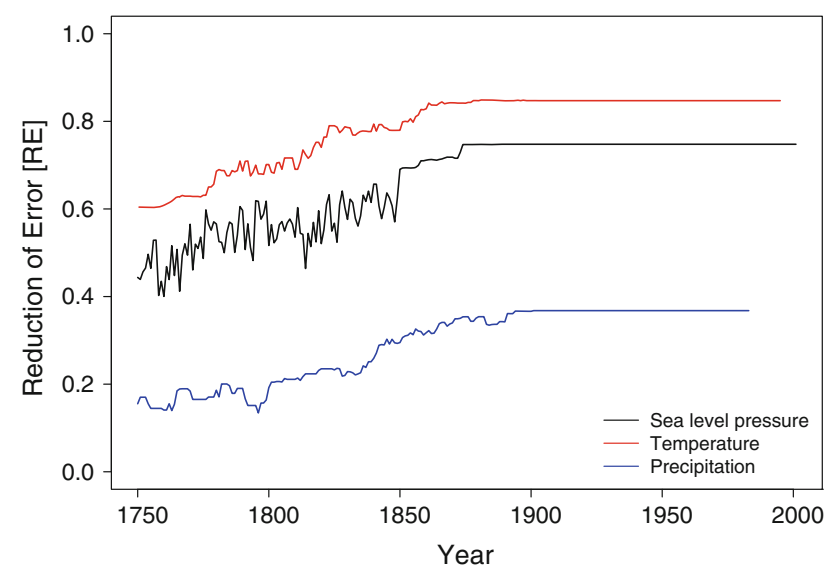

Fig. 1 Field averaged reduction of error (RE; Cook et al. 1994) values for European winter (DJF) mean temperature (Luterbacher et al. 2007; 1750-1995; red), precipitation (Pauling et al. 2006; 17501983; blue) and SLP (Küttel et al. 2009; 1750-2000; black). Values above zero indicate better performance than climatology, 1 indicates perfect skill a new classification algorithm based on simulated annealing and diversified randomization (SANDRA). This method uses the clustering technique of simulated annealing which allows each member of a cluster to change to another cluster at any time, even if the within-cluster similarity might decrease at first (Philipp et al. 2007). In SANDRA, this technique is combined with the concept of diversified randomization, i.e. the simulated annealing is repeated 1,000 times with the starting clusters being randomized at each iteration and the ordering of the clusters as well as objects also being randomized throughout the process of checking and reassigning (Philipp et al. 2007). In their application on daily resolved North Atlantic and European SLP fields back to 1850 , Philipp et al. (2007) showed that SANDRA yields better results in terms of within-class similarity and between-class separation than other commonly used clustering techniques such as k-means. This method was also used by Jacobeit et al. (2009) and Jones and Lister (2009) to investigate, on a daily basis, the changes in the relationship between the larger North Atlantic/European pressure field and European temperature and precipitation during the periods 1850-2003 and 1901-2000, respectively. We classified the SLP fields by Küttel et al. (2009) using i.a. SANDRA, k-means (e.g. Brönnimann et al. 2007) and partitioning around medoids (PAM) clustering (e.g. Beranová and Huth 2008) as well as t-mode principal component analysis (e.g. Jacobeit et al. 2003). The highest within-cluster similarity and between-cluster separation was obtained for SANDRA (not shown). Therefore, this is the method chosen to classify the winter SLP fields 1750-2000.

The determination of the optimal number of clusters is a crucial part in every clustering technique. Various methods were suggested (see Philipp et al. 2007 for a recent overview). However, none was found to be the best for all applications. We therefore apply here a straightforward approach by calculating SANDRA for different numbers of clusters. The highest within-class correlations were obtained for nine clusters. The same number of clusters has been reported for winter season by Philipp et al. (2007) though using daily SLP fields covering the period 1850 2003. In order to check for years which can hardly be assigned to a specific cluster, the silhouette index by Kaufman and Rousseeuw (1990) was used. Based on the dissimilarity matrix, negative silhouette widths indicate members that cannot be clearly allocated to a cluster (Kaufman and Rousseeuw 1990). Applying this technique to the nine SLP clusters derived from SANDRA, 30 winters were found to have negative silhouette widths. In order to minimize the SLP variability within the clusters, these years were eliminated prior to the analysis. Members from all of the nine clusters were removed. Almost one third of them are in cluster 1 . An overview of the final clusters is given in Table 1, demonstrating that the within-cluster 
correlations are generally well above 0.9 , all being statistically highly significant $(p<0.001)$.

The temperature (Luterbacher et al. 2007) and precipitation (Pauling et al. 2006) fields 1750-2000 were also split into nine clusters accordingly to the assignment of the SLP fields to the nine SLP clusters. The within-cluster stability of the SLP, temperature, and precipitation clusters was determined by calculating scaled mean anomaly composites (Brown and Hall 1999). The significance of the composites was assessed by a modified $t$-test (Brown and Hall 1999). Scaled mean anomaly composites are more robust to outliers than simple mean composites since the associated variance of the members is also included. Furthermore, this method can also be applied to non-gaussian distributed data (Brown and Hall 1999). Scaled mean anomaly composites in paleoclimatic applications have recently been presented by Touchan et al. (2005), Brönnimann et al. (2007), and Esper et al. (2007).

Finally, in order to quantitatively assign multidecadal changes in temperature and precipitation to frequency and within-type variations of the SLP clusters, the decomposition methodology by Barry and Perry (1973) is used. Therein, the climate difference $\Delta \bar{C}$ between two periods is defined as

$\Delta \bar{C}=\sum_{i=1}^{G}\left[\left(\Delta F_{i}\left(C_{i}+\Delta C_{i}\right) / n\right)+\left(F_{i} \cdot \Delta C_{i} / n\right)\right]$

where

$G=$ number of clusters

$F_{i}=$ absolute frequency of cluster $i$ during the first period

Table 1 Overview of the nine SLP clusters obtained using the SANDRA classification algorithm by Philipp et al. (2007). The second column indicates the initial number of members in the clusters, while the third column refers to the final number after eliminating those with a negative silhouette width (Kaufman and Rousseeuw 1990, see text for details). The fourth and fifth columns present the minimum and median of the within-cluster correlations of the final sets, all significant at $p<0.001$

\begin{tabular}{llllll}
\hline \multirow{2}{*}{ Cluster } & \multicolumn{2}{l}{ Members } & & & \multicolumn{2}{l}{ Within-cluster correlation } \\
\cline { 2 - 3 } & Initial & Final & & Minimum & Median \\
\hline 1 & 34 & 25 & & 0.91 & 0.97 \\
2 & 33 & 29 & & 0.81 & 0.96 \\
3 & 32 & 28 & & 0.91 & 0.98 \\
4 & 31 & 28 & & 0.82 & 0.97 \\
5 & 30 & 26 & & 0.87 & 0.97 \\
6 & 28 & 25 & & 0.70 & 0.90 \\
7 & 25 & 24 & & 0.88 & 0.98 \\
8 & 20 & 19 & & 0.75 & 0.93 \\
9 & 18 & 17 & 0.65 & 0.94 \\
\hline
\end{tabular}

$C_{i}=$ climatic mean of cluster $i$ during the first period $\Delta F_{i}=$ difference in the absolute frequency of cluster $i$ between the second and the first period

$\Delta C_{i}=$ difference in the climatic mean of cluster $i$ between the second and the first period

$n=$ number of time units during the first period

The expression $\left(\Delta F_{i}\left(C_{i}+\Delta C_{i}\right) / n\right)$ describes the change in climate between two periods which is related to variations in the frequency of the SLP clusters, i.e. an observed warming (cooling) might be due to the more frequent appearance of warm (cold) clusters. Accordingly, the expression $\left(F_{i} \cdot \Delta C_{i} / n\right)$ describes differences in the climate of two periods related to a changed relationship between the SLP clusters and climate, i.e. changes due to withintype variations (see Sect. 1). This method was used by Beck (2000) and Beck et al. (2007) to decompose the monthly changes in Central European mean temperature and precipitation 1780-1995. Here, multidecadal changes, i.e. European temperature and precipitation averaged over 50-year periods, are compared with each other and decomposed. The length of fifty years was chosen in order to have for each cluster a sufficient number of members. Results will only be presented for the difference in temperature and precipitation between the 1950-1999 period and the preceding 50-year periods 1750-1799, 1800-1849, 1850-1899, and 1900-1949. Therefore, the second period in Eq. (1) is 1950-1999. Because some of the winters were removed due to negative silhouette widths (see above), the number of winters per cluster $n$ changes for each 50-year period. Equation (1) is applied to all grid boxes of the temperature reconstruction by Luterbacher et al. (2007) and the precipitation reconstruction by Pauling et al. (2006). This allows quantifying spatially the degree to which changes in temperature and precipitation are due to variations in the frequency of the SLP clusters or due to withintype modulations.

\section{Results and discussion}

Figure 2 shows mean composites of the absolute winter SLP fields (left) as well as scaled mean SLP, temperature, and precipitation anomaly composites for the nine clusters

Fig. 2 SLP clusters derived using the SANDRA clustering technique (Philipp et al. 2007) and corresponding temperature (Luterbacher et al. 2007) and precipitation (Pauling et al. 2006) fields. The frequency of each cluster over the period 1750-2000 is indicated to the left. Columns 2-4 are scaled mean composites of the anomalies (Brown and Hall 1999) with regard to 1750-2000. The grey shaded areas (SLP) and the green contour lines (temperature and precipitation) indicate significance at the $95 \%$ level using the modified $t$-test by Brown and Hall (1999). The units of columns 2-4 are dimensionless 


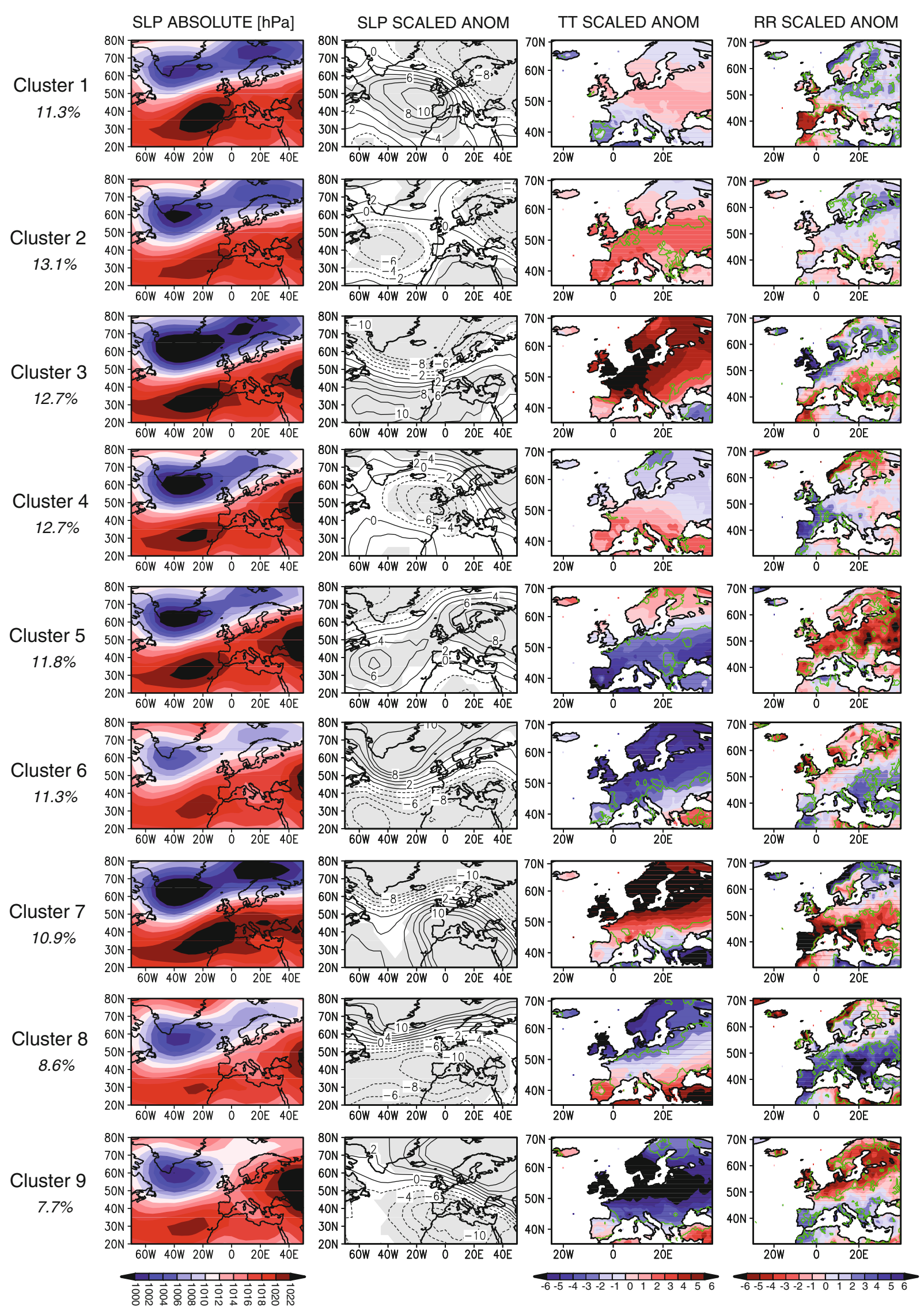


over the period 1750-2000. All anomalies are with respect to the 1750-2000 climatology. The $95 \%$ significance level (as determined from the modified $t$-test, see Brown and Hall 1999) is indicated by the grey shaded areas (SLP) and the green contour lines (temperature and precipitation). The SLP anomaly clusters presented in Fig. 2 (second column) can be characterized as being predominantly zonally (clusters $3,6,7,8$ ), half-meridionally $(1,9)$, or meridonally $(2,4,5)$ oriented. Clusters 3 and 7 are connected with anomalous westerly winds while anomalous easterly advection dominates in clusters 6 and 8. Cluster 1 is characterized by anomalous northwesterly circulation directed toward Europe while anomalous southeasterly flow is prevalent in cluster 9.

Simplified, the anomalous westerly and northwesterly patterns might be referred to as positive modes of the North Atlantic Oscillation (NAO), while the anomalous easterly and southeasterly patterns represent variations of the negative mode. The meridional clusters 2, 4, and 5 are more complex patterns with anomalously low (high) pressure over the southern North Atlantic and Western Russia/ Scandinavia (Greenland and Northern Africa) in cluster 2 and opposite conditions in cluster 5. Anomalously low pressure is found over the Bay of Biscay in cluster 4. These clusters represent situations with NAO values fluctuating around zero. As indicated by the grey shaded areas in Fig. 2 (second column), all of the nine SLP clusters are very robust patterns, i.e. the members of each cluster differ not significantly from each other. This is of importance since it allows dynamic interpretations henceforth which are not strongly affected by high within-cluster SLP variations.

The temperature and precipitation distribution related to the nine SLP clusters (Fig. 2) indicates that the patterns with anomalous westerly (clusters 3, 7) and northwesterly (1) circulation generally lead to above (below) normal temperatures and precipitation across Northern Europe (parts of the Mediterranean). However, important spatial differences due to the latitudinal position, strength, and direction of the anomalous westerly winds are visible. The patterns with anomalous easterly $(6,8)$ and southeasterly (9) winds are generally connected with the advection of anomalously cold and dry air masses toward Northern Europe while parts of the Mediterranean region experience anomalously mild and wet winters. The patterns 2 (5) with anomalous meridional circulation are related with above (below) normal temperatures and precipitation across Europe, while cluster 4 reveals above (below) normal temperatures and precipitation over southwestern Europe (Scandinavia).

\subsection{Frequency changes}

Figure 3 shows the decadal changes in the frequency of the nine SLP clusters over the period 1750-2000. To simplify the interpretation, $C$ and $W$ in Fig. 3 indicate whether a particular SLP cluster is mainly related to anomalously cold (clusters 5, 6, 8, and 9) or warm (clusters 2, 3, and 7) conditions in Europe (see Fig. 2). The European temperature field is more heterogeneous during clusters 1 and 4 (Fig. 2). In order to characterize the precipitation field, the plus (minus) signs in Fig. 3 indicate that a particular SLP cluster shows enhanced westerly (easterly) flow connected with generally above (below) normal precipitation amounts over Northern Europe and anomalously dry (wet) conditions over Southern Europe (Fig. 2).

Although all clusters show decadal changes in their frequency (Fig. 3), no significant $(p<0.05)$ trends could be found over the 1750-2000 period. However, there are some interesting features, e.g. the prolonged absence of the cold and dry cluster $5(1760-1810$ s) and the very cold cluster 9 (1850-1890s). However, these decades are not found to be anomalously warm in the temperature reconstruction by Luterbacher et al. (2007). As can be depicted from Fig. 3 this is partly due to the fact that their absence is compensated by the more frequent appearance of other SLP clusters connected with cooler temperatures across Europe. However, even the decades with $50 \%$ or more of all years belonging to a cold cluster (1750s, 1760s, 1840s, 1890s, 1960s) were not all significantly colder than average in Luterbacher et al. (2007). Similarly, the decades with a predominance of anomalously warm clusters (1790s, 1810s, 1910s, 1920s, 1990s) were not all warmer than normal. This disagreement might be surprising at first but can be explained by within-type variations, i.e. a particular SLP pattern can be connected with distinctly different temperature and precipitation anomalies (see next section). The decadal changes in the frequency of SLP patterns related with anomalous westerly (plus signs in Fig. 3) or easterly (minus signs in Fig. 3) flow reveals a better agreement with the precipitation fields reconstructed by Pauling et al. (2006). These changes reflect well the known relationship between the strength of the westerlies and the precipitation distribution across Europe (e.g. Hurrell and Van Loon 1997). For example, the decade 1960-1969 (1920-1929) with a predominance of SLP patterns related with anomalous easterly (westerly) flow (Fig. 3) was indeed wetter (drier) than normal over parts of the Mediterranean. The precipitation anomalies during these periods were of opposite sign over Northern Europe (Pauling et al. 2006).

\subsection{Within-type variations}

As stated above, the European temperature and precipitation fields related to a particular SLP pattern might have changed their characteristics over time. The validity of this hypothesis is next assessed by calculating the spatial 


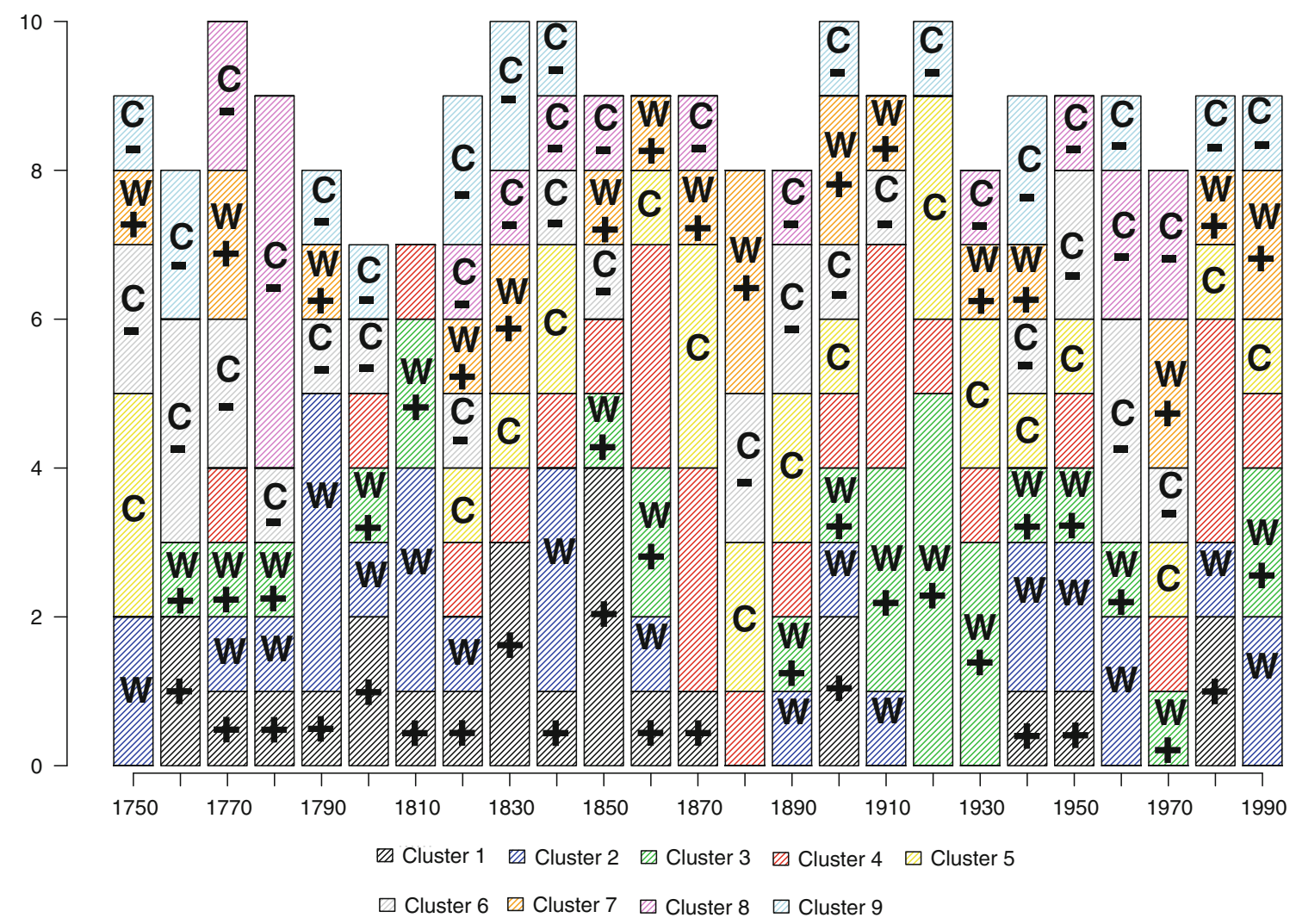

Fig. 3 Decadal frequency of the SLP clusters for the winters 17502000. $W(C)$ indicates that the cluster is related to generally warmer (colder) than normal conditions in Europe, while $+(-)$ denote

average temperature and precipitation for each cluster and member (Fig. 4).

Figure 4 clearly shows that a particular SLP pattern can be related to distinctly different European mean temperatures (Fig. 4; upper panels) and precipitation (Fig. 4; lower panels). Interestingly, a tendency toward warmer and wetter conditions over the past 250 years is observed for some of the clusters. This agrees well with other studies which found that European winters became warmer and generally wetter (drier over parts of the Mediterranean) during the last couple of decades (e.g. Klein Tank et al. 2002; Jones and Moberg 2003; Luterbacher et al. 2004, 2007; Xoplaki et al. 2004; Casty et al. 2005; Pauling et al. 2006). Using the Mann-Kendall test, these positive trends over the period 1750-2000 were found to be statistically significant at $p<0.05$ for clusters $3,4,5$, and 7 (temperature) and for clusters 3, 4, and 6 (precipitation). However, none of the clusters shows a significant $(p<0.05)$ trend when only the period 1900-2000 — where the most pronounced changes are observed-is considered. This highlights the strong dependence of trends on the length of the period under consideration and on the starting point of the presumed trend (e.g. Percival and Rothrock 2005; Matti et al. 2009). Nevertheless, these findings demonstrate that anomalous westerly (easterly) advection. The missing years (i.e. the bars are smaller than ten) represent the years where the SLP field could not be assigned to a particular cluster (see Sect. 3)

the temperature and precipitation fields show important within-type variations. The deviations in temperature and precipitation from their respective long-term mean (Fig. 4) appear to be largest during the last few decades. This agrees well with the study of Beck et al. (2007) who found that January changes related to within-type variations in Europe became predominant over frequency-related changes around 1860 for temperature and around 1900 for precipitation.

Because of the high spatial variability of particularly precipitation (see Fig. 2), it is problematic to consider only spatial means. We therefore calculated for 50 -year periods and each of the nine clusters scaled mean anomaly composites of the European temperature (Fig. 5) and precipitation (Fig. 6) fields.

Figure 5 shows the scaled mean anomaly composites of the European temperature field over 50-year periods. Important spatio-temporal temperature variations are found for all nine clusters, demonstrating that all clusters are subject to considerable within-type variations. Furthermore, the derived 50-year composites are only statistically significant for some regions and clusters (green contour lines in Fig. 5). This indicates that the temperature fields corresponding to a particular SLP pattern differ strongly from 

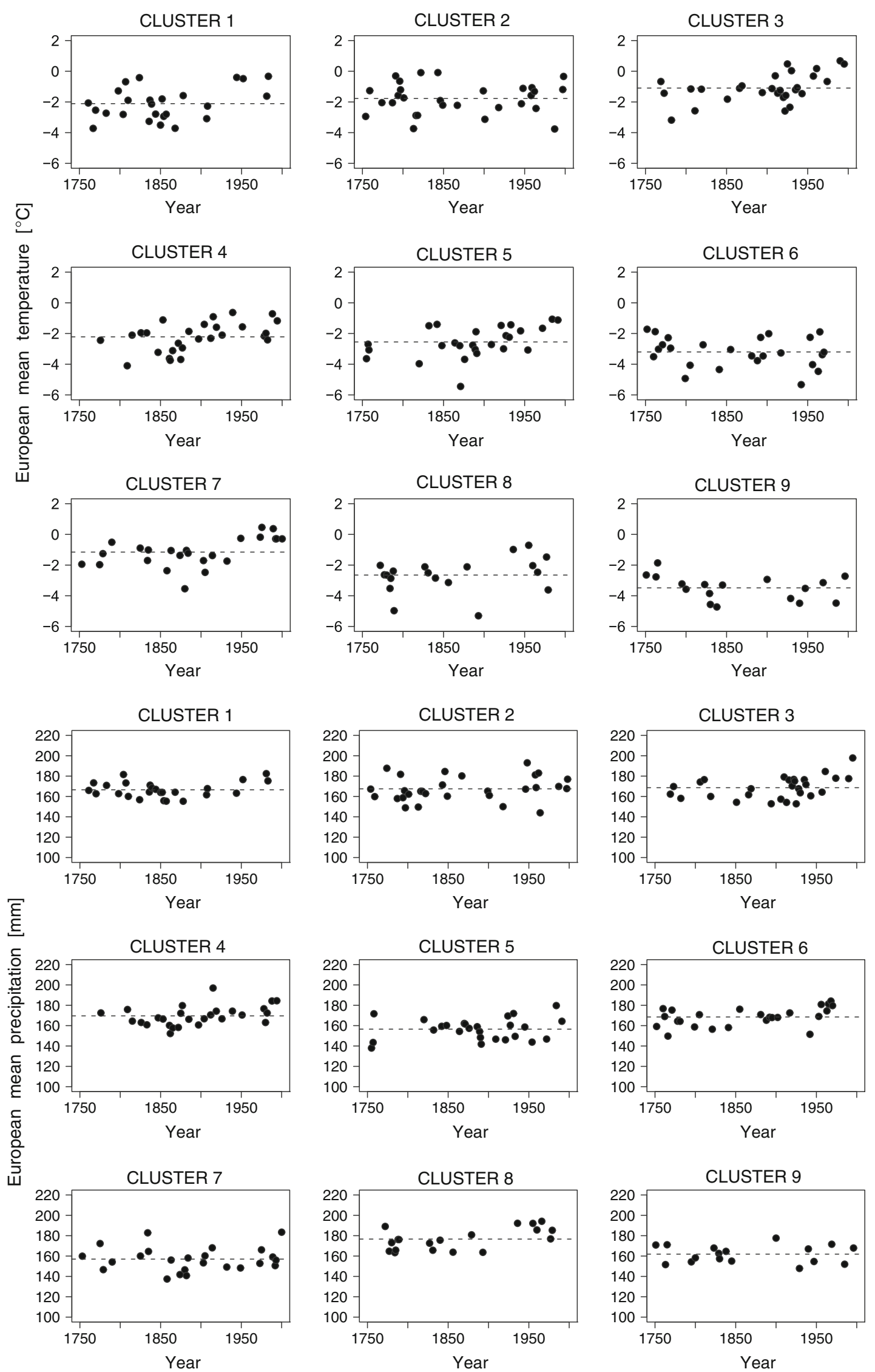
4 Fig. 4 Averaged European winter mean temperature (Luterbacher et al. 2007, top) and precipitation (Pauling et al. 2006, bottom) for each SLP cluster and member. The dashed horizontal lines indicate the mean temperature and precipitation for each cluster, respectively

each other, even within the 50-year periods. Nevertheless, the general tendency toward warmer temperatures (cf. Fig. 4; upper panels) can also be detected in Fig. 5. Additionally, the period 1950-1999 (Fig. 5; right column) appears to be the overall warmest for most clusters. However, the degree of warming is spatially very diverse: while clusters 1, 5, and 7 have mostly become warmer over Scandinavia and Eastern Europe/Western Russia, the warming is strongest over Central Europe and the Mediterranean in clusters 4 and 8 (Fig. 5). The tendency to higher temperatures is found for all types of atmospheric circulation, i.e. for zonal, half-meridional, and meridional clusters.

The multidecadal changes in the SLP-precipitation relationship are shown in Fig. 6. As for temperature, considerable temporal and spatial changes in the precipitation fields related to a particular SLP pattern are visible. Due to the high spatial variability of the European precipitation field, the tendency toward wetter conditions found in Fig. 4 (lower panels) can hardly be recognized in Fig. 6. At the most, it might be speculated that some parts of Europe have become wetter in 1950-1999, as e.g. Scandinavia in cluster 3 or Central and Western Europe in cluster 8. Therefore, it can only be stated that the general precipitation pattern found over 1750-2000 (Fig. 2) is maintained in most clusters. However, considerable changes in the precipitation amounts (e.g. clusters 3, 5 and 7 during 1850-1899) take place. Within-type variations are therefore also clearly revealed for precipitation.

\subsection{Decomposing multidecadal temperature and precipitation variations}

The presented results indicate that large parts of the changes in European temperatures and precipitation are likely due to within-type variations. Using the methodology by Barry and Perry (1973, see Sect. 3), we decomposed the temperature (Fig. 5) and precipitation (Fig. 6) changes between 50-year periods into parts related to frequency and within-type variations. Here, only the temperature and precipitation differences between the 1950-1999 average and the means of the preceding 50-year periods are studied. The results obtained for temperature are shown in Fig. 7, those for precipitation in Fig. 8. The estimations of the percentage of temperature and precipitation changes due to frequency and due to within-type-related variations (black contour lines in Figs. 7 and 8) are based on the absolute values of the corresponding temperature and precipitation changes.
The winter average temperatures for the most recent 50year period were in almost all regions of Europe higher than during the preceding 50-year periods (Fig. 7; left column, see also Luterbacher et al. 2004, 2007). The multidecadal temperature changes due to variations in the frequency of the SLP patterns (Fig. 7; middle column) are generally small. Interestingly, the changes in the frequency of the SLP clusters from 1900-1949 to 1950-1999 actually led to overall cooler conditions in 1950-1999 (Fig. 7; centre column, bottom row). Frequency-related changes are only found dominant for some regions and periods, e.g. for the UK relative to 1900-1949 and for Turkey compared with 1800-1849 and 1900-1949. Hence, most of the multidecadal temperature changes are related to within-type variations (Fig. 7; right column). Within-type variations are of particular importance for Eastern Europe and Scandinavia, accounting for more than $80 \%$ of 50 -year mean winter temperature changes. The predominance of within-type variations appears to be strongest comparing 1950-1999 with $1850-1899$ and weakest relative to $1750-1799$.

The decomposition results for precipitation are shown in Fig. 8. The 1950-1999 period appears to be overall wetter than the preceding 50-year periods, except for parts of the Mediterranean area which show driest conditions during this period (Fig. 8, left column). This agrees well with the results presented in Fig. 4 (lower panels). However, considerable spatial and temporal differences are visible: For instance, the Scandinavian west coast was remarkably drier during 1950-1999 than during 1850-1899 (Fig. 8, left column, third row). This might be related to a higher frequency of clusters 1 and 7 during 1850-1899 (circulation patterns related to anomalous westerly and northwesterly flow toward Europe; Figs. 2 and 3) advecting humid air masses to western Scandinavia. Indeed, the middle column of Fig. 8 reveals that frequency-related variations in precipitation over western Scandinavia between 1850-1899 and 1950-1999 dominate over within-type-related variations (black contour lines and labels). Overall, the parts of European precipitation changes due to frequency and due to within-type variations are more balanced than for temperature (Fig. 7), with a slight dominance of within-type variations particularly over Eastern Europe/Western Russia.

These findings-for temperature as well as precipitation-agree well with earlier studies, all pointing toward a predominance of within-type-related variations over those due to frequency changes (e.g. Widmann and Schär 1997; Brinkmann 1999; Beck 2000; Yarnal et al. 2001; Jacobeit et al. 2003, 2009; Beck et al. 2007; Jones and Lister 2009). However, while the cited studies were based on spatial averages or single station information, the considerable spatial differences in Figs. 7 and 8 clearly reveal the necessity to consider the full field information. The percentage of European climate variations due to within-type 

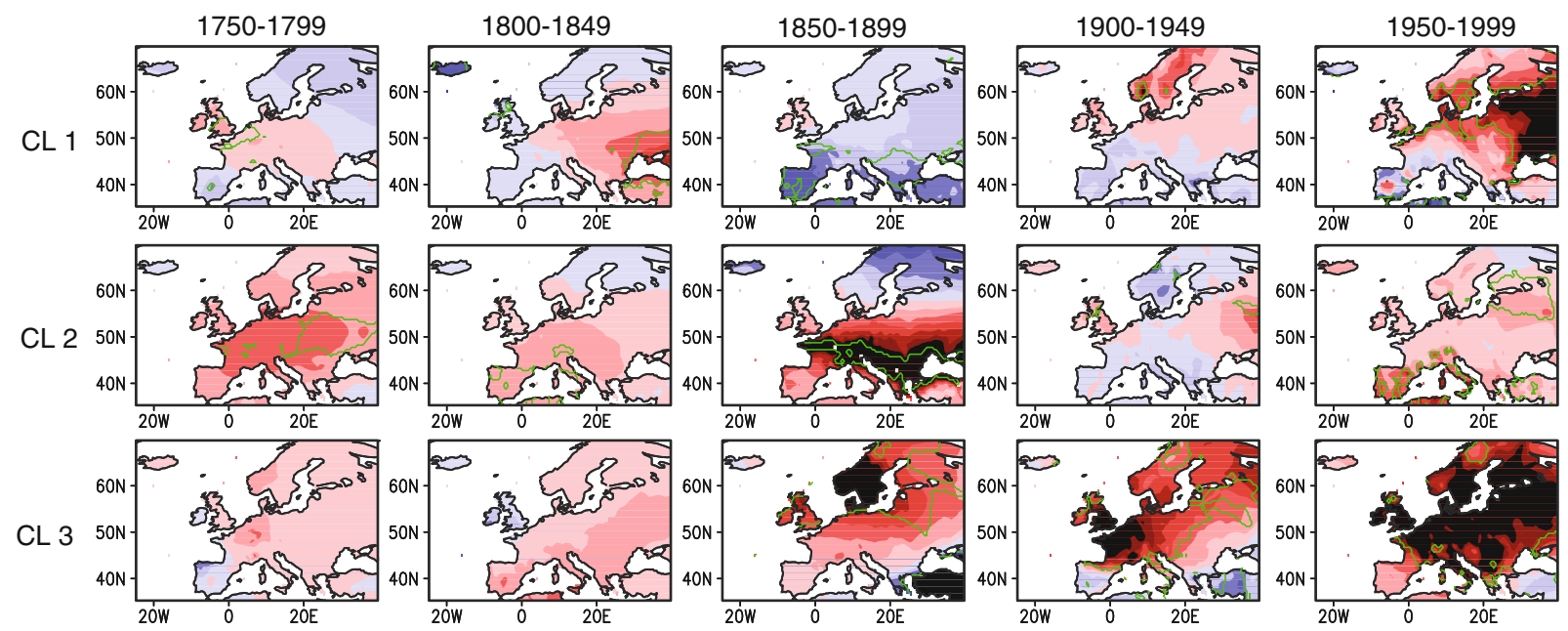

CL 4
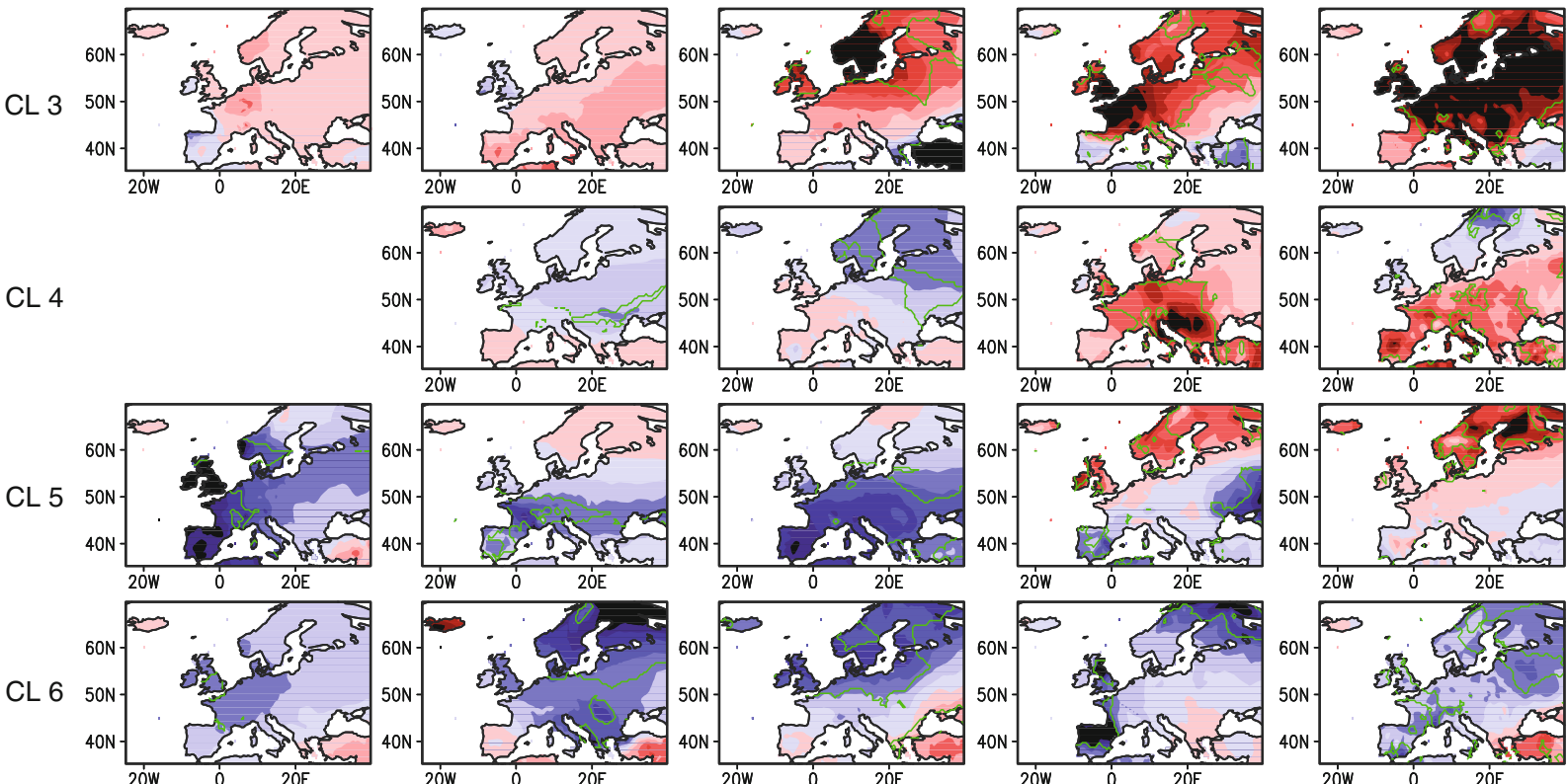

CL 7
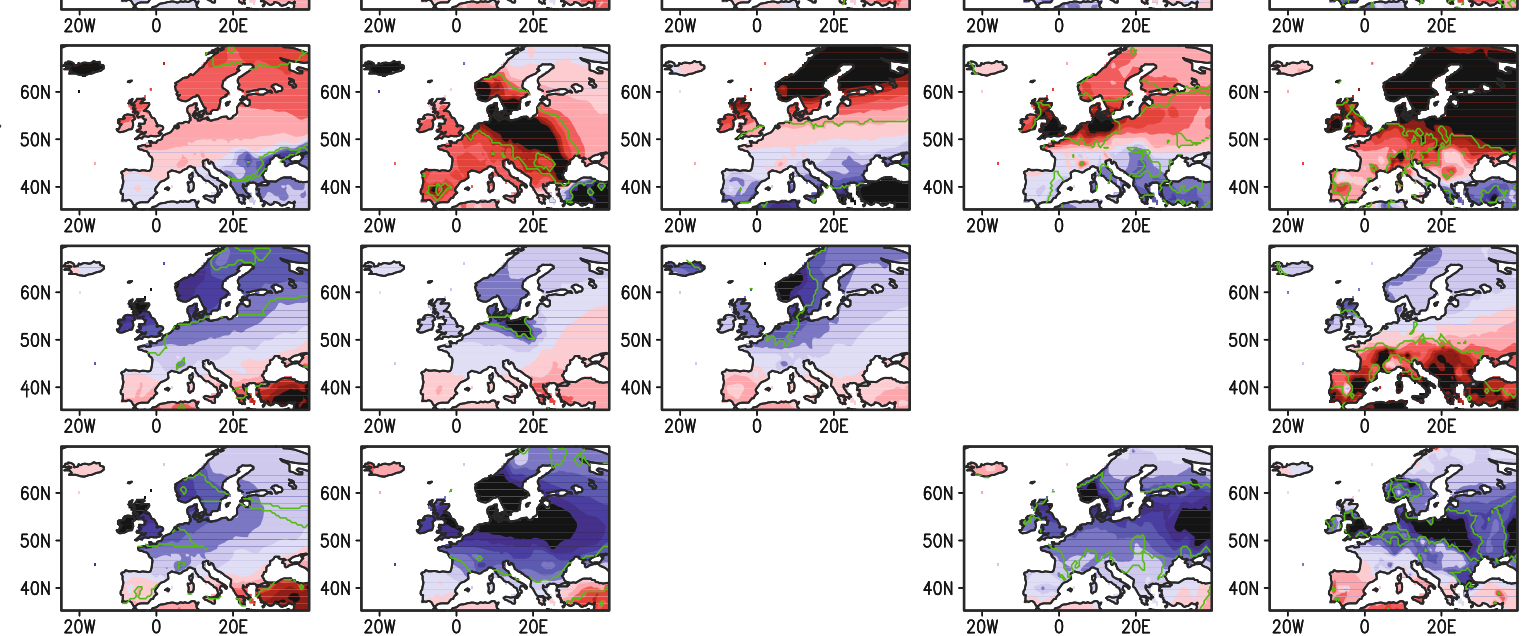

Fig. 5 50-year scaled mean anomaly composites (wrt 1750-2000) of the temperature reconstruction by Luterbacher et al. (2007) split according to the nine winter SLP clusters derived from Küttel et al. (2009). Red (blue) denotes anomalously warm (cold) winters. The green lines indicate significance at the $95 \%$ level using the modified

$t$-test by Brown and Hall (1999). Blank fields represent periods where a particular SLP cluster is only found once or is absent, not allowing the calculation of scaled mean anomaly composites. The units are dimensionless

changes of the SLP clusters found in this work slightly differs from earlier studies cited above. We suggest that this is mostly related to differences in the spatial area and temporal resolution of the datasets considered, including their skill.

\subsection{Sources of within-type variations}

Sources of within-type variations can generally be separated into those of dynamical and those of climatic origin 

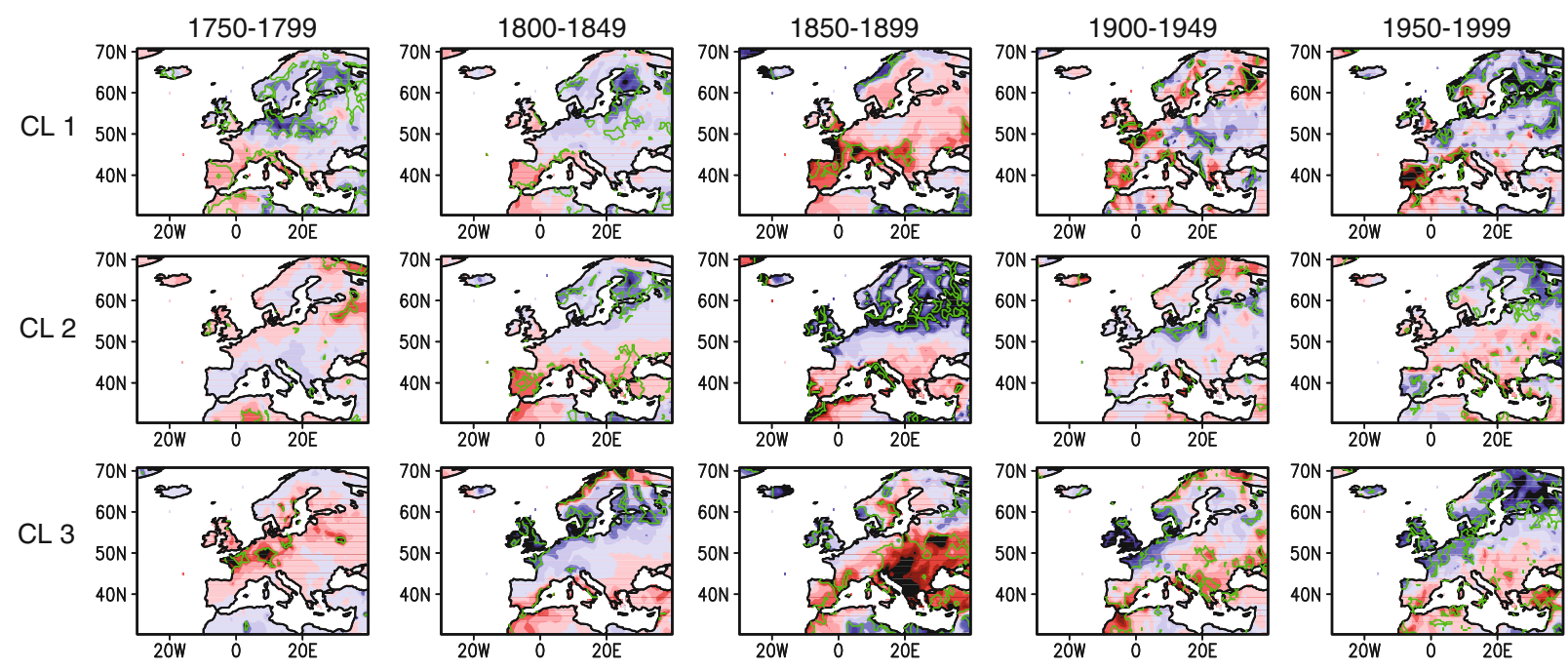

CL 4
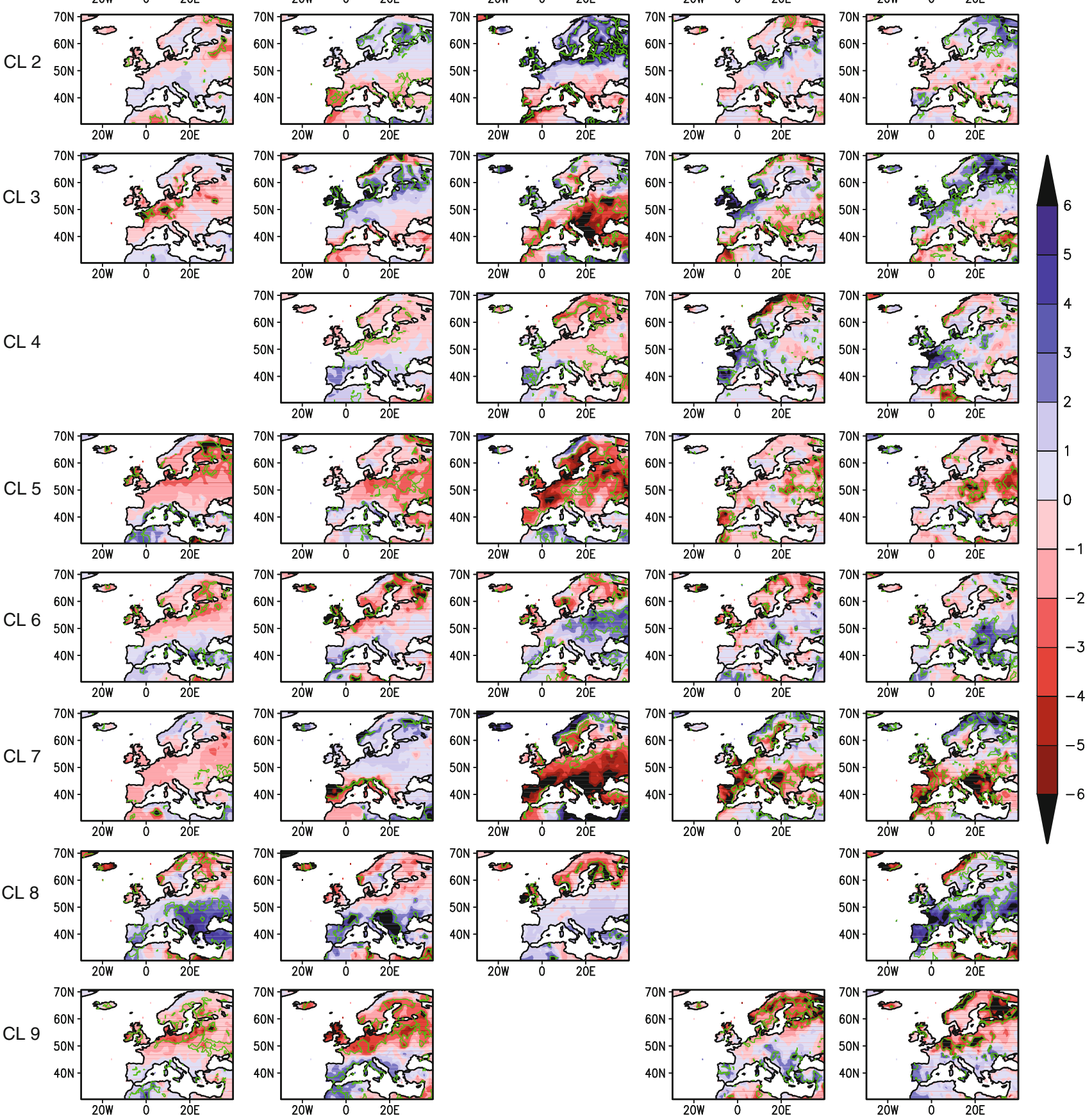

Fig. 6 As Fig. 5 but for winter precipitation (Pauling et al. 2006). Red (blue) indicates anomalously dry (wet) winters with respect to the 17502000 reference period

(e.g. Beck et al. 2007). Subsequently, possible sources of within-type variations in the present study are shortly addressed and evaluated.
Uncertainties of the SLP, temperature, and precipitation reconstructions might be expected to be an important contributor to dynamical as well as climatic within-type 

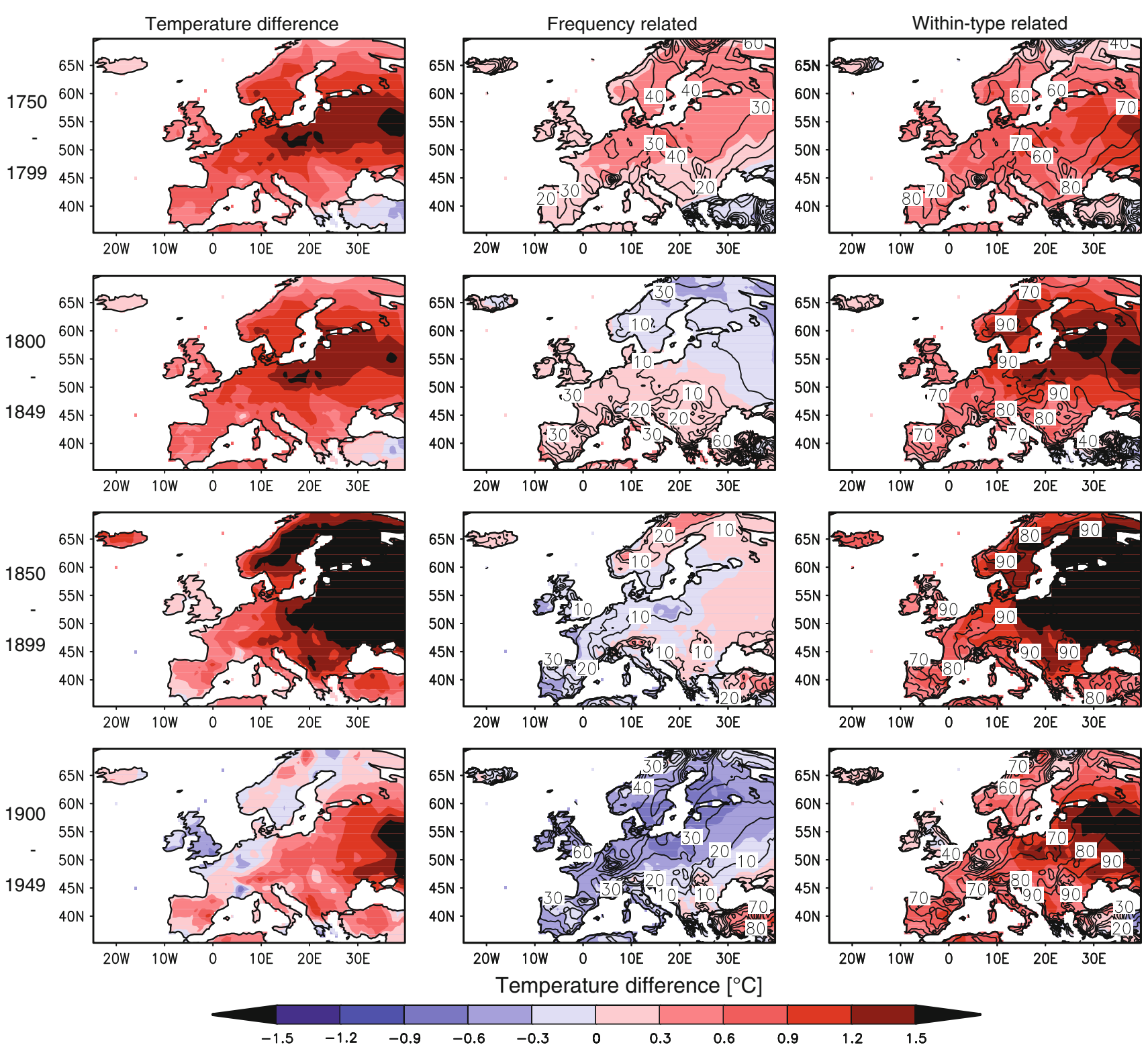

Fig. 7 Absolute temperature differences (in ${ }^{\circ} \mathrm{C}$ ) between the 1950 1999 winter average and the preceding 50-year periods (left column), temperature differences between the 1950-1999 winter average and the preceding 50-year periods due to variations in SLP cluster frequency (middle column) and due to within-type variations of the
SLP clusters (right column). Reddish (bluish) colours indicate that the winters 1950-1999 were on average warmer (colder) than the preceding 50-year period. The contours and labels indicate the percentages of the absolute temperature changes which are frequency and within-type-related, respectively variations. This means that the changes in the SLPtemperature/precipitation relationship simply arise from deficiencies in the reconstructions themselves. One would thus expect within-type variations to become more important further back in time as the uncertainties in the reconstructions increase. However, within-type variations were found to be of equal or even higher importance during the latest decades, i.e. the period covered by the instrumental dataset of Mitchell and Jones (2005; see Sect. 2).

Within-type variations of dynamical origin may stem from the rather coarse $5^{\circ} \times 5^{\circ}$ resolution of the SLP reconstruction by Küttel et al. (2009) which limits the proper representation of small-scale features of the atmospheric circulation. Indeed, Jones and Lister (2009) found that subgrid-scale effects originating from orography or land-sea contrast can strongly contribute to within-type variations. Additionally, processes working on a shorter timescale than resolved in this study, e.g. extreme daily precipitation amounts induced by a short-lived pressure field, might not be resolved in the seasonal SLP fields. As a further source of dynamical within-type variations, it was found in this study that the pressure gradient between the 

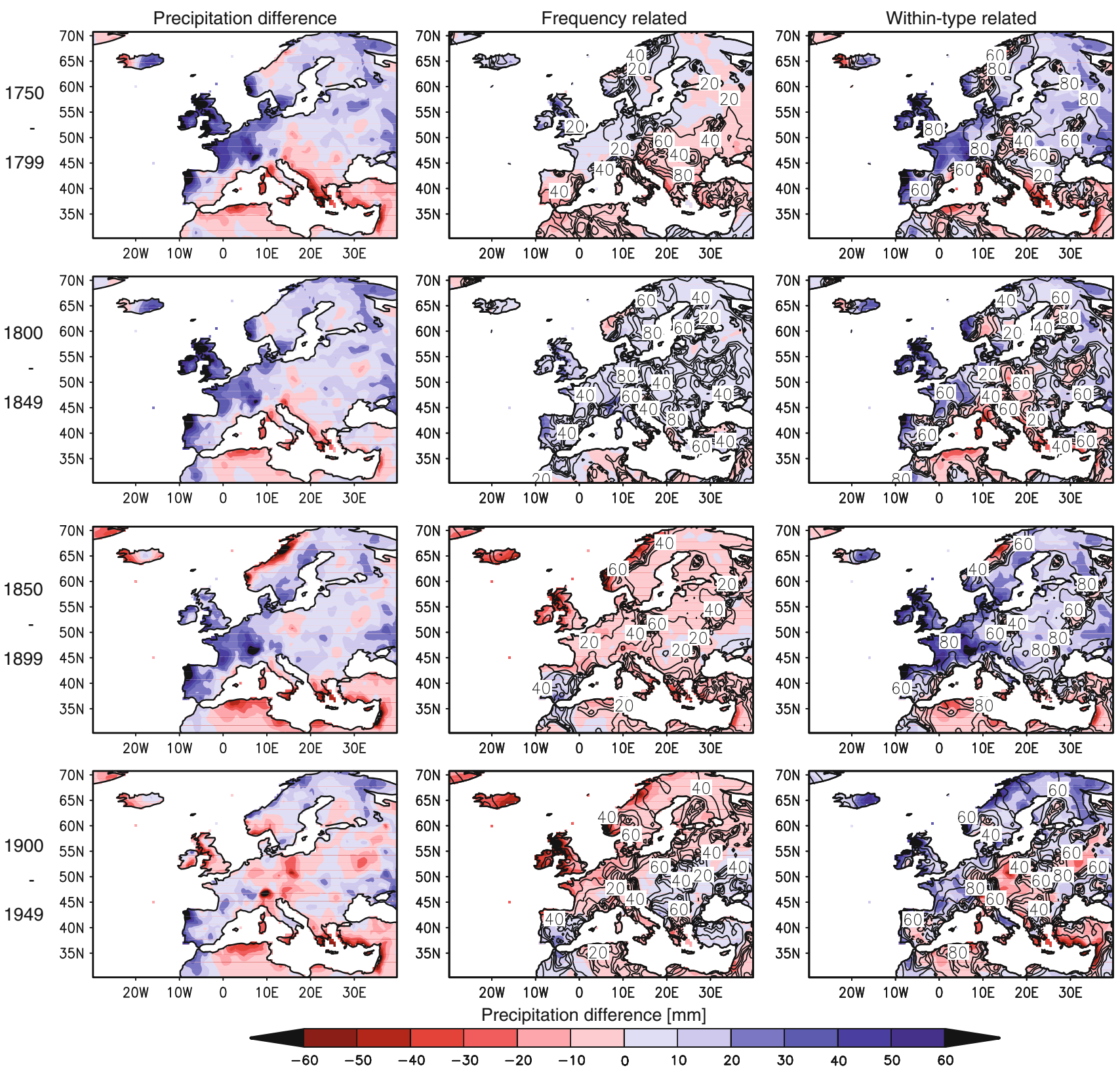

Fig. 8 As Fig. 7 but for precipitation. Reddish (bluish) values indicate that 1950-1999 was on average drier (wetter) than the preceding 50-year period

Azores High and the Icelandic Low has slightly increased during the last few decades (not shown). This leads to stronger westerlies which might be related to the overall winter warming and wetting of Europe (drying in parts of the Mediterranean area, mainly in the western realm; e.g. Xoplaki et al. 2004). However, the increase in the pressure gradient is small and not found for all SLP clusters (not shown). This agrees with the study by Beck et al. (2007) who found an increase in the intensity but also vorticity of some Grosswettertypes over the last few decades which, however, cannot fully explain the changes in Central European mean temperature and precipitation.
Accordingly, it must be assumed that significant parts of the observed within-type variations originate from changed climatic boundaries. As was suggested by Stahl et al. (2006), these climatic changes might stem from internal oscillations such as the El Niño Southern Oscillation (ENSO) which, through teleconnections, might change the climatic boundary conditions over Europe in late winter (e.g. Brönnimann et al. 2007). Important contributions to this type of within-type variations might also arise from changes in the North Atlantic sea surface temperatures (SSTs) which are known to strongly influence European climate (e.g. Kushnir and Held 1996; Rodwell et al. 1999; 
Wanner et al. 2001; Sutton and Hodson 2005; Della-Marta et al. 2007; Compo and Sardeshmukh 2009). The recent study by Parker (2009) demonstrated that increased SSTs significantly contribute to within-type variations in Central England temperatures. However, results in this study showed that within-type variations are of similar importance in all SLP patterns, i.e. also in those related with advection from predominantly continental areas. Finally, climatic within-type variations might also stem from an increased forcing due to anthropogenic emissions (e.g. IPCC 2007). One would thereby expect the percentages of temperature and precipitation changes due to within-type variations to increase over the past 250 years. However, the presented results did not reveal any tendency in this direction.

\section{Conclusions}

European winter climate is known to be strongly influenced by the state of the large-scale atmospheric circulation. Here, the changes in the relationship between classified SLP data (Küttel et al. 2009) and independent field reconstructions of European winter temperatures (Luterbacher et al. 2007) and precipitation (Pauling et al. 2006) were investigated over the period 1750-2000. A particular focus was on spatially assessing changes in European temperature and precipitation due to changed frequencies and due to within-type variations of the SLP clusters, respectively. This study is therefore an advance on earlier studies that focused on spatial means or station information.

It was shown that all of the nine derived SLP clusters are subject to important decadal to multidecadal frequencyvariations with none indicating significant long-term trends. However, for most of the SLP clusters a tendency toward warmer and wetter (drier) European (parts of the Mediterranean) winters was found, most strongly expressed within the last fifty years. This indicates important withintype variations, i.e. the relationship between patterns of the large-scale atmospheric circulation and European climate is subject to considerable non-stationarities. These nonstationarities should therefore be considered in every kind of study transferring changes in circulation to changes in climate. Using a decomposition scheme it has been shown that large parts of multidecadal temperature and precipitation changes can be related to within-type variations. This is particularly true for temperature and Eastern Europe/Scandinavia with within-type variations explaining more than $80 \%$ of the long-term changes. Accordingly, only a small part of the observed changes in winter temperatures and precipitation over the past 250 years are due to changed frequencies of the SLP clusters. The origin of the within-type variations can be manifold with no particular source found to be the most relevant.

In the context of the debate on the origin of the recently observed climate change, it is of great importance to assess and quantify the origin of within-type variations in more detail than done in this study. Future research should therefore particularly work in this direction by e.g. using climate model simulations.

Acknowledgments The authors thank Andreas Philipp and Christoph Beck (University of Augsburg, Germany) for the SANDRA algorithm and helpful information. The reviewers' comments helped to further improve the quality of the paper. Marcel Küttel has been supported by the Swiss National Science Foundation (SNSF) through its National Centre of Competence in Research on Climate (NCCR Climate) project PALVAREX 2. Jürg Luterbacher acknowledges support from the 7th EU Framework program ACQWA (Assessing Climate Impacts on the Quantity and Quality of Water, http://www.acqwa.ch/, \# 212250).

\section{References}

Allan R, Ansell T (2006) A new globally complete monthly historical gridded mean sea level pressure dataset (HadSLP2): 1850-2004. J Clim 19:5816-5842

Barry RG, Perry AH (1973) Synoptic climatology: methods and applications. Methuen, London, p 552

Beck C (2000) Zirkulationsdynamische Variabilität im Bereich Nordatlantik-Europa seit 1780. Würzburger Geographische Arbeiten 95, p 350

Beck C, Jacobeit J, Jones PD (2007) Frequency and within-type variations of large-scale circulation types and their effects on low-frequency climate variability in Central Europe since 1780. Int J Climatol 27:473-491

Beranová R, Huth R (2008) Time variations of the effects of circulation variability modes on European temperature and precipitation in winter. Int J Climatol 28:139-158

Brinkmann WAR (1999) Within-type variability of $700 \mathrm{hPa}$ winter circulation patterns over the Lake Superior basin. Int J Climatol 19:41-58

Brönnimann S, Xoplaki E, Casty C, Pauling A, Luterbacher J (2007) ENSO influence on Europe during the last centuries. Clim Dyn 28:181-197

Brown TJ, Hall BL (1999) The use of t values in climatological composite analyses. J Clim 12:2941-2944

Casty C, Handorf D, Sempf M (2005) Combined winter climate regimes over the North Atlantic/European sector 1766-2000. Geophys Res Lett 32:L13801. doi:10.1029/2005GL022431

Compo GP, Sardeshmukh PD (2009) Oceanic influences on recent continental warming. Clim Dyn 32:333-342

Cook E, Briffa K, Jones PD (1994) Spatial regression methods in dendroclimatology. A review and comparison of two techniques. Int J Climatol 14:379-402

Della-Marta PM, Luterbacher J, von Weissenfluh H, Xoplaki E, Brunet M, Wanner H (2007) Summer heat waves over western Europe 1880-2003, their relationship to large-scale forcings and predictability. Clim Dyn 29:251-275

Esper J, Frank D, Büntgen U, Verstege A, Luterbacher J, Xoplaki E (2007) Long-term drought severity variations in Morocco. Geophys Res Lett 34:L17702. doi:10.1029/2007GL030844

Haylock MR, Jones PD, Allan RJ, Ansell TJ (2007) Decadal changes in 1870-2004 Northern Hemisphere winter sea level pressure 
variability and its relationship with surface temperature. J Geophys Res 112:D11103. doi:10.1029/2006JD007291

Hess P, Brezowsky H (1952) Katalog der Grosswetterlagen Europas. Berichte des Deutschen Wetterdienstes in der US-Zone 5, p 39

Hurrell JW, Van Loon H (1997) Decadal variations in climate associated with the North Atlantic Oscillation. Clim Change 36:301-326

Huth R, Beck C, Philipp A, Demuzere M, Ustrnul Z, Cahynová M, Kyselý J, Tveito OE (2008) Classifications of atmospheric circulation patterns: recent advances and applications. Ann NY Acad Sci 1146:105-152

IPCC (2007) Climate change 2007: the physical science basis. Contribution of working group I to the fourth assessment report of the intergovernmental panel on climate change. Cambridge University Press, Cambridge, p 996

Jacobeit J (2009) Classifications in climate research. Phys Chem Earth. doi:10.1016/j.pce.2009.11.010

Jacobeit J, Jönsson P, Bärring L, Beck C, Ekström M (2001) Zonal indices for Europe 1780-1995 and running correlations with temperature. Clim Change 48:219-241

Jacobeit J, Wanner H, Luterbacher J, Beck C, Philipp A, Sturm K (2003) Atmospheric circulation variability in the North-AtlanticEuropean area since the mid-seventeenth century. Clim Dyn 20:341-352

Jacobeit J, Rathmann J, Philipp A, Jones PD (2009) Central European precipitation and temperature extremes in relation to large-scale atmospheric circulation types. Meteorol Z 18:397-410

Jones PD, Lister DH (2009) The influence of the circulation on surface temperature and precipitation patterns over Europe. Clim Past 5:259-267

Jones PD, Moberg A (2003) Hemispheric and large-scale surface air temperature variations: an extensive revision and an update to 2001. J Clim 16:206-223

Jones PD, Davies TD, Lister DH, Slonosky V, Jónsson T, Bärring L, Jönsson P, Maheras P, Kolyva-Machera F, Barriendos M, Martin-Vide J, Rodriguez R, Alcoforado MJ, Wanner H, Pfister C, Luterbacher J, Rickli R, Schuepbach E, Kaas E, Schmith T, Jacobeit J, Beck C (1999) Monthly mean pressure reconstructions for Europe for the 1780-1995 period. Int J Climatol 19:347-364

Kaufman L, Rousseeuw PJ (1990) Finding groups in data: an introduction to cluster analysis. Wiley, New York, p 368

Klein Tank AMG, Wijngaard JB, Können GP, Böhm R, Demarée G, Gocheva A, Mileta M, Pashiardis S, Hejkrlik L, Kern-Hansen C, Heino R, Bessemoulin P, Müller-Westermeier G, Tzanakou M, Szalai S, Pálsdóttir T, Fitzgerald D, Rubin S, Capaldo M, Maugeri M, Leitass A, Bukantis A, Aberfeld R, Van Engelen AFV, Forland E, Mietus M, Coelho F, Mares C, Razuvaev V, Nieplova E, Cegnar T, López JA, Dahlström B, Moberg A, Kirchhofer W, Ceylan A, Pachaliuk O, Alexander LV (2002) Daily dataset of 20th-century surface air temperature and precipitation series for the European Climate Assessment. Int $\mathrm{J}$ Climatol 22:1441-1453

Kushnir Y, Held IM (1996) Equilibrium atmospheric response to North Atlantic SST anomalies. J Clim 9:1208-1220

Küttel M, Xoplaki E, Gallego D, Luterbacher J, García-Herrera R, Allan R, Barriendos M, Jones PD, Wheeler D, Wanner H (2009) The importance of ship log data: reconstructing North Atlantic, European and Mediterranean sea level pressure fields back to 1750. Clim Dyn Online First. doi: 10.1007/s00382-009-0577-9

Lamb HH (1972) British Isles weather types and a register of the daily sequence of circulation patterns. Geophys Mem 16, p 85

Lund IA (1963) Map-pattern classification by statistical methods. J Appl Meteorol 2:56-65

Luterbacher J, Rickli R, Tinguely C, Xoplaki E, Schüpbach E, Dietrich D, Hüsler J, Ambühl M, Pfister C, Beeli P, Dietrich U,
Dannecker A, Davies TD, Jones PD, Slonosky V, Ogilvie AEJ, Maheras P, Kolyva-Machera F, Martin-Vide J, Barriendos M, Alcoforado MJ, Nunez F, Jónsson T, Glaser R, Jacobeit J, Beck C, Philipp A, Beyer U, Kaas E, Schmith T, Bärring L, Jönsson P, Rácz L, Wanner H (2000) Reconstruction of monthly mean sea level pressure over Europe for the Late Maunder Minimum period (1675-1715). Int J Climatol 20:1049-1066

Luterbacher J, Rickli R, Xoplaki E, Tinguely C, Beck C, Pfister C, Wanner H (2001) The Late Maunder Minimum (1675-1715)—a key period for studying decadal scale climatic change in Europe. Clim Change 49:441-462

Luterbacher J, Xoplaki E, Dietrich D, Rickli R, Jacobeit J, Beck C, Gyalistras D, Schmutz C, Wanner H (2002) Reconstruction of sea level pressure fields over the Eastern North Atlantic and Europe back to 1500 . Clim Dyn 18:545-561

Luterbacher J, Dietrich D, Xoplaki E, Grosjean M, Wanner H (2004) European seasonal and annual temperature variability, trends, and extremes since 1500. Science 303:1499-1503

Luterbacher J, Liniger MA, Menzel A, Estrella N, Della-Marta PM, Pfister C, Rutishauser T, Xoplaki E (2007) Exceptional European warmth of autumn 2006 and winter 2007: historical context, the underlying dynamics, and its phenological impacts. Geophys Res Lett 34:L12704. doi:10.1029/2007GL029951

Luterbacher J, Koenig SJ, Franke J, van der Schrier G, Zorita E, Moberg A, Jacobeit J, Della-Marta PM, Küttel M, Xoplaki E, Wheeler D, Rutishauer T, Stössel M, Wanner H, Brázdil R, Dobrovolný $\mathrm{P}$, Camuffo $\mathrm{D}$, Bertolin $\mathrm{C}$, van Engelen $\mathrm{A}$, Gonzalez-Rouco FJ, Wilson R, Pfister C, Limanówka D, Nordli $\varnothing$, Leijonhufvud L, Söderberg J, Allan R, Barriendos M, Glaser R, Riemann D, Hao Z, Zerefos CS (2010) Circulation dynamics and its influence on European and Mediterranean January-April climate over the past half millennium: results and insights from instrumental data, documentary evidence and coupled climate models. Clim Change. doi:10.1007/s10584-009-9782-0

Matti C, Pauling A, Küttel M, Wanner H (2009) Winter precipitation trends for two selected European regions over the last 500 years and their possible dynamical background. Theor App Climatol 95:9-26. doi:10.1007/s00704-007-0361-x

Mitchell TD, Jones PD (2005) An improved method of constructing a database of monthly climate observations and associated highresolution grids. Int J Climatol 25:693-712

Parker DE (2009) Anomalies of central England temperature classified by air source. J Clim 22:1069-1081

Pauling A, Luterbacher J, Casty C, Wanner H (2006) Five hundred years of gridded high-resolution precipitation reconstructions over Europe and the connection to large-scale circulation. Clim Dyn 26:387-405

Percival DB, Rothrock DA (2005) "Eyeballing" trends in climate time series: a cautionary note. J Clim 18:886-891

Philipp A, Della-Marta PM, Jacobeit J, Fereday DR, Jones PD, Moberg A, Wanner H (2007) Long-term variability of daily North Atlantic-European pressure patterns since 1850 classified by simulated annealing clustering. J Clim 20:4065-4095

Pozo-Vázquez D, Esteban-Parra MJ, Rodrigo FS, Castro-Díez Y (2001) A study of NAO variability and its possible non-linear influences on European surface temperature. Clim Dyn 17:701715

Rodwell MJ, Rowell DP, Folland CK (1999) Oceanic forcing of the wintertime North Atlantic Oscillation and European climate. Nature 398:320-323

Schmutz C, Wanner H (1998) Low frequency variability of atmospheric circulation over Europe between 1785 and 1994. Erdkunde 52:81-94

Slonosky VC, Jones PD, Davies TD (2001) Atmospheric circulation and surface temperature in Europe from the 18th century to 1995. Int J Climatol 21:63-75 
Stahl K, Moore RD, McKendry IG (2006) The role of synoptic-scale circulation in the linkage between large-scale ocean-atmosphere indices and winter surface climate in British Columbia, Canada. Int J Climatol 26:541-560

Sutton RT, Hodson DLR (2005) Atlantic Ocean forcing of North American and European summer climate. Science 309:115-118

Touchan R, Xoplaki E, Funkhouser G, Luterbacher J, Hughes MK, Erkan N, Akkemik U, Stephan J (2005) Reconstructions of spring/summer precipitation for the Eastern Mediterranean from tree-ring widths and its connection to large-scale atmospheric circulation. Clim Dyn 25:75-98

Trenberth KE (1995) Atmospheric circulation climate changes. Clim Change 31:427-453

Vicente-Serrano SM, López-Moreno JI (2008) Nonstationary influence of the North Atlantic Oscillation on European precipitation. J Geophys Res Atmos 113:D20120. doi:10.1029/2008JD010382
Walker GT, Bliss EW (1932) World Weather V. Mem R Meteor Soc $4: 53-84$

Wanner H, Brönnimann S, Casty C, Gyalistras D, Luterbacher J, Schmutz C, Stephenson DB, Xoplaki E (2001) North Atlantic oscillation-concepts and studies. Surv Geophys 22:321-381

Widmann M, Schär C (1997) A principal component and long-term trend analysis of daily precipitation in Switzerland. Int $\mathrm{J}$ Climatol 17:1333-1356

Xoplaki E, González-Rouco FJ, Luterbacher J, Wanner H (2004) Wet season Mediterranean precipitation variability. Influence of large-scale dynamics. Clim Dyn 23:63-78

Yarnal B (1993) Synoptic climatology in environmental analysis-a primer. Belhaven Press, London, p 256

Yarnal B, Comrie AC, Frakes B, Brown DP (2001) Developments and prospects in synoptic climatology. Int J Climatol 21:1923-1950 